lan C. Bickle, MB BCh BAO, FRCR

Department of Radiology

RIPAS Hospital,

Bandar Seri Begawan

Brunei
Correspondence: Dr. lan C. Bickle

Department of Radiology

RIPAS Hospital

Bandar Seri Begawan BA1710

Brunei Darrusalam

Tel: (673) 8612182

Fax: (673) 2242690

Email: ian@bickle.co.uk

Reprints will not be available from the author.

The author declared that this represents original material that is not being considered for publication or has not been published or accepted for publication elsewhere, in full or in part, in print or electronic media; that the manuscript has been read and approved by the author, that the requirements for authorship have been met by the author, and that the author believes that the manuscript represents honest work.

Disclosures: The author signed a disclosure that there are no financial or other (including personal) relationships, intellectual passion, political or religious beliefs, and institutional affiliations that might lead to a conflict of interest.

\section{Complete Dislocation of the Lens of the Eye - Always Review the Complete Study}

This 37 year-old male patient underwent high resolution $\mathrm{CT}$ imaging of the face including paranasal sinuses following trauma.

Computed tomography (CT) has a well-established role in the assessment of the facial bones in the context of trauma, in particular for fractures involving the paranasal sinuses and orbit. High resolution imaging permits isotropic reconstruction in multiple planes. Its use in imaging the contents of orbit itself is more select, with both direct clinical examination and even orbital ultrasound used to assess the globe and lens of the eye. ${ }^{1}$

Traumatic dislocation of the lens of the eye may entail the partial or complete translocation of the lens from its normal position within the anterior aspect of the eye. ${ }^{2}$ The high attenuation lens 'floats', within the vitreous of the globe (Figures 1,2 and 3).

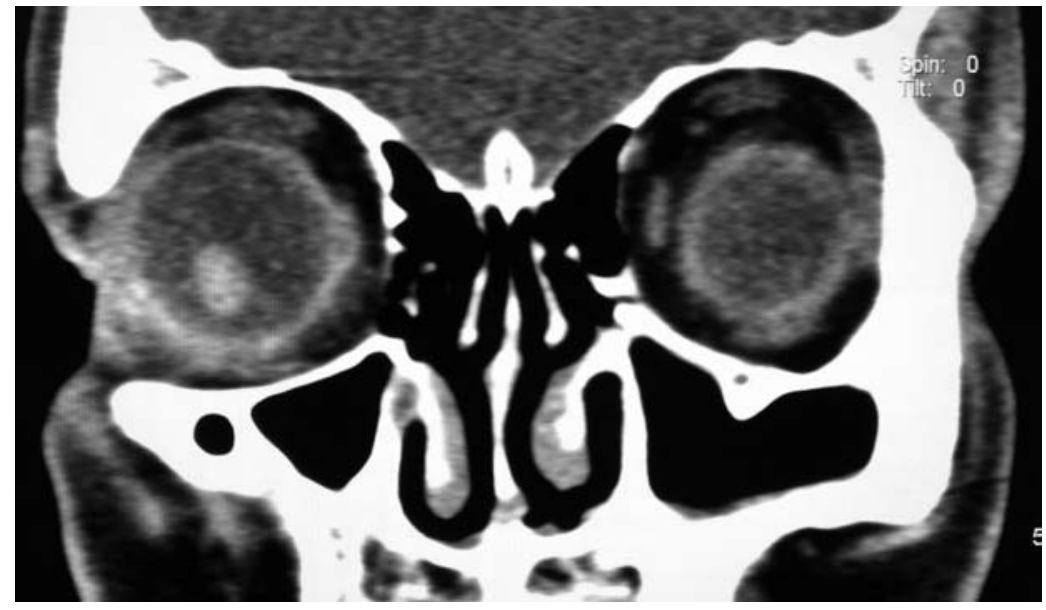

Figure 1. Coronal CT of the Orbit. The lens of the right eye lies posteriorly within the globe of the eye (arrow) in keeping with a lens dislocation. 
Following trauma to the face the injuries may be multiple and cross sub-speciality boundaries, but one should be alert to all injuries. In reviewing $\mathrm{CT}$ images one should be forensic in the review of all the anatomy covered, even it is not related to the original clinical query or not pertinent to one's own clinical speciality.

As an old mentor once told me, 'Before you take the film down, have one last paranoid look.'

Learning Point: Always review the entirety of the imaging performed despite the focus of one's clinical or speciality interest.

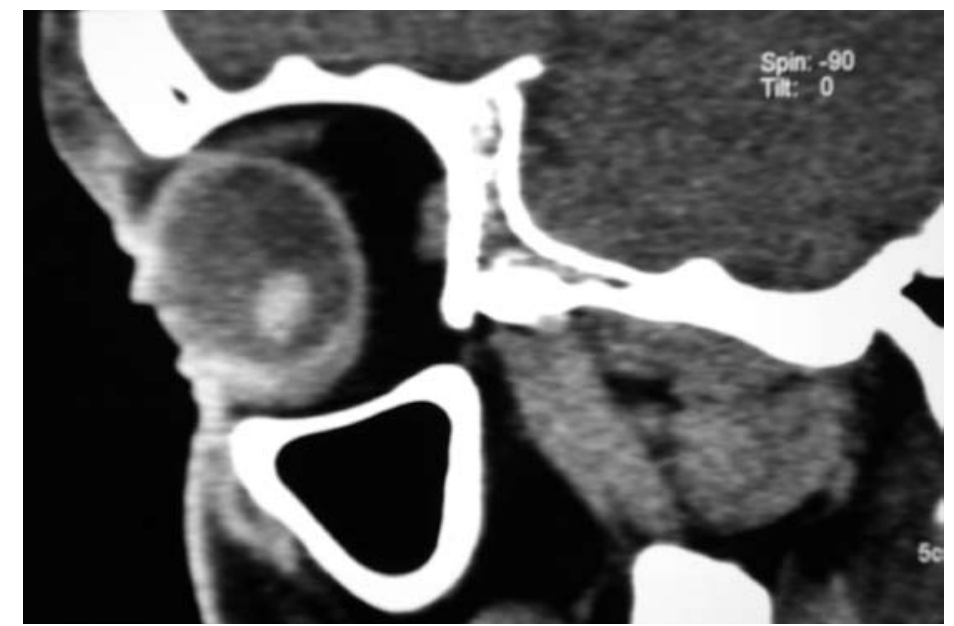

Figure 2. Sagittal CT of the Orbit. The lens of the right eye (arrow) is situated posteriorly within the globe of the eye.

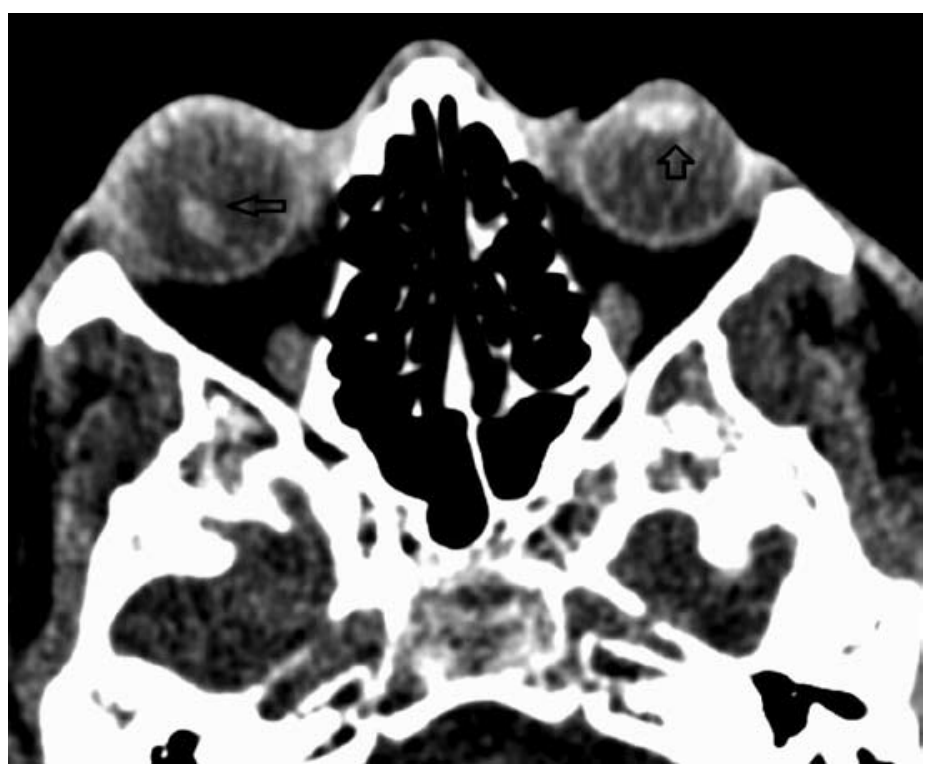

Figure 3. Axial CT of the orbits. Note the dislocated right lens (horizontal arrow); compare with the normal position of the left lens of the eye (vertical arrow).

\section{REFERENCES}

1. Kubal WS. Imaging of Orbital Trauma. Radiographics. 2008; 28: 1729-1739

2. Hardjasudarma M, Rivera E, Ganley JP, McClellan RL. Computed tomography of traumatic dislocation of the lens. Emerg Radiol. 1994; 1: 180-182 